\title{
Mechanical Properties of Steel Fiber-Reinforced Concrete by Vibratory Mixing Technology
}

\author{
Yuanxun Zheng $\mathbb{D},{ }^{1,2}$ Xiaolong $W u,{ }^{1}$ Guangxian $H e,{ }^{3}$ Qingfang Shang, ${ }^{3}$ Jianguo Xu $\mathbb{D},{ }^{1}$ \\ and Yikai Sun ${ }^{1}$ \\ ${ }^{1}$ School of Water Conservancy and Environment, Zhengzhou University, Zhengzhou, Henan 450001, China \\ ${ }^{2}$ Henan Traffic Investment Group Co. Ltd., Zhengzhou, Henan 450052, China \\ ${ }^{3}$ Henan Wanli Road \& Bridge Group Co. Ltd., Xuchang, Henan 461000, China \\ Correspondence should be addressed to Yuanxun Zheng; yxzheng@zzu.edu.cn and Jianguo Xu; jianguoxu@zzu.edu.cn
}

Received 2 February 2018; Accepted 2 April 2018; Published 12 July 2018

Academic Editor: Song Han

Copyright (C) 2018 Yuanxun Zheng et al. This is an open access article distributed under the Creative Commons Attribution License, which permits unrestricted use, distribution, and reproduction in any medium, provided the original work is properly cited.

\begin{abstract}
As a kind of important engineering material, steel fiber-reinforced concrete was used widely in civil engineering. Up to now, steel fiber-reinforced concrete was usually produced by the traditional mixing method. For the reason of uniform distribution of fiber, the reinforcement of mechanical properties of concrete was inadequately performed. In this paper, C50 steel fiber-reinforced concrete and C60 steel fiber-reinforced concrete were manufactured by traditional mixing and vibratory mixing methods, respectively, and then, the cube compression test, flexural test, splitting tensile test, and the bending test were carried out. The reinforcement effects of mechanical properties were analyzed by comparing the traditional mixing and vibratory mixing methods. The results show that vibratory mixing can effectively improve the distribution of steel fibers in concrete and can increase the density of steel fiber concrete, and therefore, it effectively improves the mechanical properties of steel fiber-reinforced concrete when compared to the traditional mixing method.
\end{abstract}

\section{Introduction}

As an important building material, concrete has been widely used in civil engineering applications such as bridges and roads engineering, and the related experimental study of the mechanical properties of concrete was also fruitful [1-5]. With the vigorous development of engineering construction, high-performance concretes such as fiber-reinforced concrete was applied gradually in important engineering structures [6-10]. Among these high-performance concretes, for the advantages of low cost, easy fabrication, and performance improvements, obviously, steel fiber-reinforced concrete was used widely in the current engineering field $[9,10]$. However, the study showed that uneven incorporation of steel fiber would affect the fluidity and uniformity of concrete mixing and even result in fiber bonding, which eventually affects the reinforcement effect of mechanical properties [11-15]. Up to now, most research paid attention on the improvement effect of different types of fiber or optimum fiber content, but little literature paid attention on the difference of improvement effect by various stirring technologies. As a kind of new stirring technology, compared to traditional stirring technology, vibratory mixing technology could effectively improve the distribution of fibers in concrete, further increase the density of steel fiber concrete, and finally improve the mechanical properties of steel fiber-reinforced concrete [16-20]. But, at present, vibratory mixing technology has not been widely used in engineering, and research on its improvement of concrete mechanical properties is inadequate at home and abroad. For such reasons, in this paper, different steel fiber incorporation volume concrete test specimens of various mix proportions were prepared, which were made by different stirring technologies. And then, compression test, flexural test, splitting tensile test, and bending test were conducted; finally, the differences of workability and mechanical properties of steel fiber concrete made by vibratory 
TABLE 1: Test mix of steel fiber concrete.

\begin{tabular}{lcccccccc}
\hline $\begin{array}{l}\text { Specimen } \\
\text { number }\end{array}$ & $\begin{array}{c}\text { Steel fiber } \\
\text { parameter } \\
(\%)\end{array}$ & $\begin{array}{c}\text { Steel fiber } \\
(\mathrm{kg})\end{array}$ & $\begin{array}{c}\text { Water } \\
(\mathrm{kg})\end{array}$ & $\begin{array}{c}\text { Cement } \\
(\mathrm{kg})\end{array}$ & $\begin{array}{c}\text { Coarse } \\
\text { aggregate } \\
(\mathrm{kg})\end{array}$ & $\begin{array}{c}\text { Fine } \\
\text { aggregate } \\
(\mathrm{kg})\end{array}$ & $\begin{array}{c}\text { Additive } \\
(\mathrm{kg})\end{array}$ & $\begin{array}{c}\text { Sand-coarse } \\
\text { aggregate } \\
\text { ratio }\end{array}$ \\
\hline \multirow{4}{*}{ C50 } & 0 & 0 & 172 & 347.5 & 1181.3 & 664.5 & 2.7 \\
& 0.5 & 39 & 172 & 347.5 & 1159.5 & 674.3 & 2.7 & 0.36 \\
& 1 & 58.9 & 172 & 347.5 & 1148.6 & 679.2 & 2.7 & 0.36 \\
& 1.5 & 78.5 & 172 & 347.5 & 1137.8 & 684.9 & 2.7 & 0.36 \\
& 2 & 117 & 172 & 347.5 & 1115.1 & 693.7 & 2.7 & 0.36 \\
C60 & 0 & 0 & 164 & 451.8 & 1078.2 & 660.8 & 4.9 & 0.36 \\
& 0.5 & 39.3 & 164 & 451.8 & 1055.8 & 671.2 & 4.9 & 0.36 \\
& 1 & 78.5 & 164 & 451.8 & 1033.5 & 681.5 & 4.9 & 0.36 \\
& 1.5 & 117.8 & 164 & 451.8 & 1011.1 & 691.9 & 4.9 & 0.36 \\
& 2 & 157 & 164 & 451.8 & 988.8 & 702.2 & 4.9 & 0.36 \\
\hline
\end{tabular}

mixing and the traditional mixing technologies, respectively, were compared and analyzed.

\section{Materials and Test Programs}

\subsection{Materials}

2.1.1. Steel Fiber. The physicochemical parameter of steel fiber should meet the requirements of JGT 472-2015. The length of steel fiber should be $20 \mathrm{~mm} \sim 60 \mathrm{~mm}$ and diameter or equivalent diameter should be $0.3 \mathrm{~mm} \sim 1.2 \mathrm{~mm}$; length to diameter ratio was 30 65.

2.1.2. Cement. P.O 42.5 ordinary Portland cement was used in this paper, and each performance index of cement and its strength of 3 days and 28 days were checked according to the performance index of "General Portland Cement" (GB1752007).

2.1.3. Fine Aggregate. Good quality graded sand was selected, and fineness modulus should be controlled in 2.3 to 3.0; fine aggregate performance was checked according to GB14684-2011.

2.1.4. Coarse Aggregate. Test selection of hard texture, graded continuous gravel, and aggregate shape with a more uniform edge polyhedron was made as well, with a particle size of $5 \mathrm{~mm} \sim 20 \mathrm{~mm}$ and clay content $<1 \%$. The "standard test method for building pebbles, gravel” (GB/T14685-2011) was used as test performance indicators of the coarse aggregate.

2.1.5. Admixture. Polycarboxylate superplasticizer was used as admixture, with water reduction rate not less than $25 \%$. The amount of admixture was $0.5 \% \sim 1 \%$ of cement content.

2.1.6. Mineral Admixture. Addition of fly ash should be consistent with the provisions of GB/T1596.

2.2. Mixture Proportion Design. The purpose of this experiment is to study the improvement of mechanical properties of different types of steel fiber-reinforced concrete (SFRC) which was made by ordinary stirring and vibratory mixing, respectively. In the field of engineering, steel fiber-reinforced concrete was always used as high-strength concrete, so in this paper, two kinds of high-strength concrete C50 and C60 were studied in this paper, and the amounts of steel fiber admixture were $0.5 \%, 1 \%, 1.5 \%$, and $2 \%$, respectively. The specific mix is shown in Table 1 .

2.3. Sample Preparation. To ensure uniform distribution of basalt fibers in the mix, sand and macadam were mixed firstly, and then, cement and fiber were added. After the mixtures were mixed for 30 seconds, the water and additives were added during the course of stirring. The stirring time of steel fiber-reinforced concrete was 3 minutes; and the mixing process is shown in Figure 1.

The prepared mixture was put into the test mold to vibrate, and then, it was made flat. The mold was removed after 48 hours maintenance, and then specimens were cured in the standard curing room at the temperature of $20^{\circ} \mathrm{C}$ and relative humidity of $97 \%$. The curing process is shown in Figure 2.

The strengthening mechanism of vibration was to make cement powder and fine material to quickly disperse; water and cement hydration reaction speed was expedited evenly so that the microscopic structure of the cement concrete was improved, and the dosage of cement was effectively reduced. The contrast of effect between vibratory mixing and traditional mixing is shown in Figure 3, and the contrast of microstructure between vibratory mixing and traditional mixing is shown in Figure 4.

\section{Experimental Programs}

3.1. Cube Compression of Steel Fiber-Reinforced Concrete. The standard length of $150 \mathrm{~mm}$ cube specimen was used in the cube compressive strength test, and the methods and procedures of "ordinary concrete mechanical properties test method standard" GB/T 50080-2016 and "test method for fiber concrete" (CECS 13-2009) were referred to conduct the test. The constant-speed stress control was used in this test, and loading speed was $0.6 \mathrm{MPa} / \mathrm{s}$; the specimen would be automatically unloaded, and the strength of damage was 


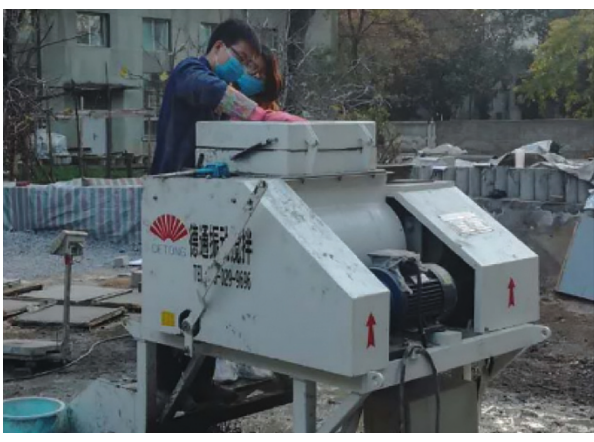

(a)

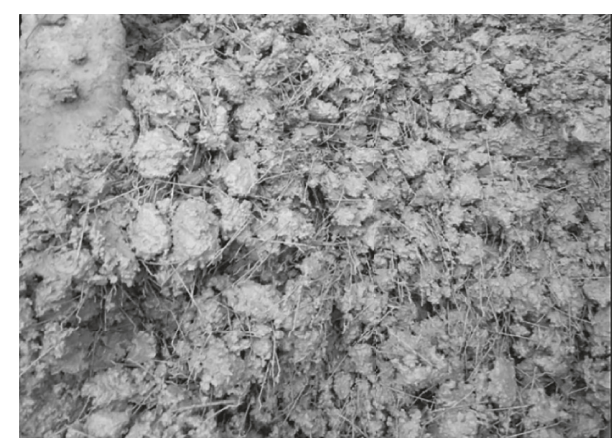

(b)

Figure 1: Mixing process of steel fiber concrete by vibratory mixing.

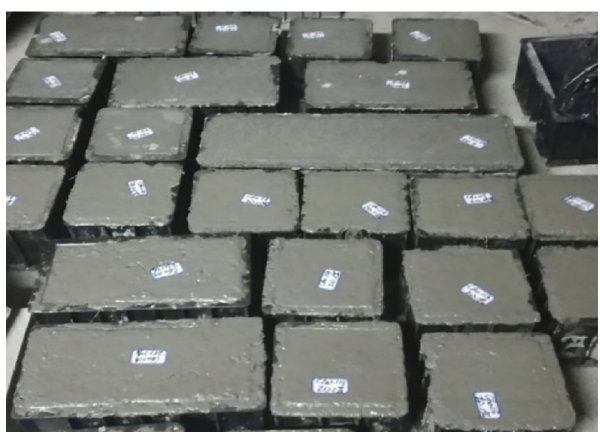

(a)

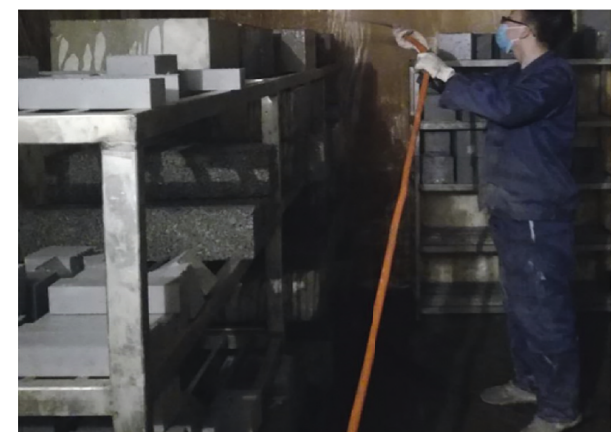

(b)

FIGURE 2: The manufacturing and curing operation of specimens.

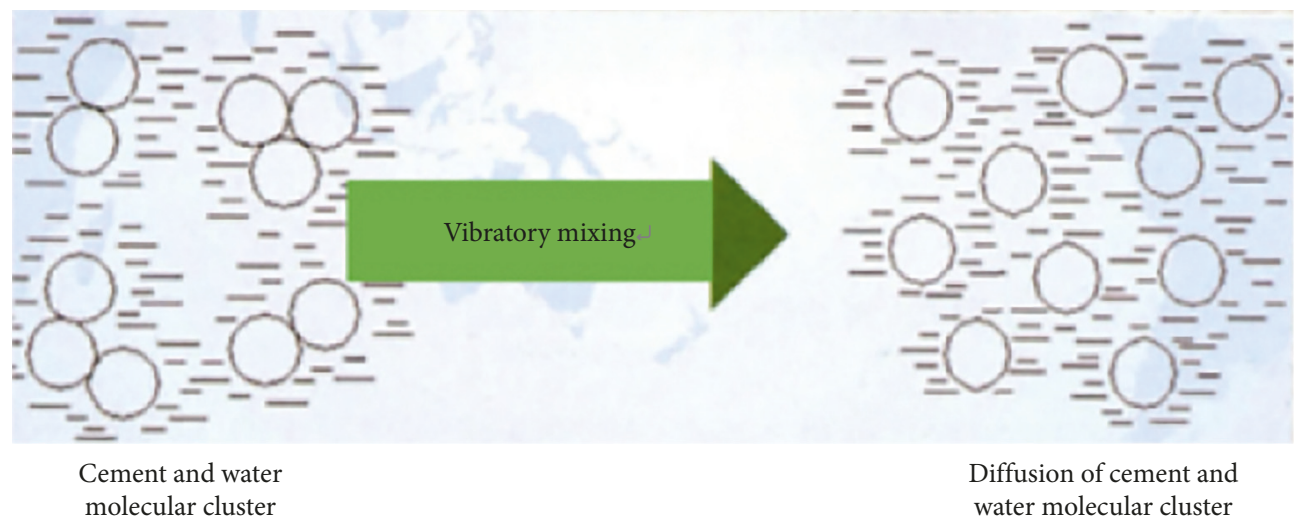

FIgURE 3: Contrast of effect between vibratory mixing and traditional mixing.

recorded by the machine. The cube compressive strength testing machine is shown in Figure 5.

3.2. Flexural Test of Steel Fiber-Reinforced Concrete. The existing literatures showed that the flexural tests of steel fiberreinforced concrete made by vibratory mixing were very limited up to now. For this purpose, a series of beam specimens (at the age of $28 \mathrm{~d}$ ) with the size of $100 \mathrm{~mm} \times 100 \mathrm{~mm} \times$ $400 \mathrm{~mm}$ were used to study the flexural strength in this study. The three-point loading tests were carried out using the flexural testing machine (NYL-300C type) in accordance with the Chinese standard (JTG E30-2005). The test apparatus of the flexural strength test is presented in Figure 6.

3.3. Split Tensile Test of Steel Fiber-Reinforced Concrete. The standard length of $150 \mathrm{~mm}$ cube specimen was used in the splitting tensile strength test, and each group includes 3 specimens. The $3000 \mathrm{kN}$ pressure testing machine was used in this test, and the splitting position should be drawn before the splitting test, as shown in Figure 7. 


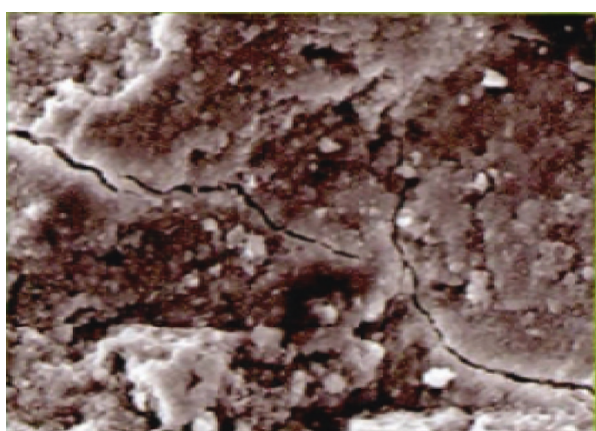

(a)

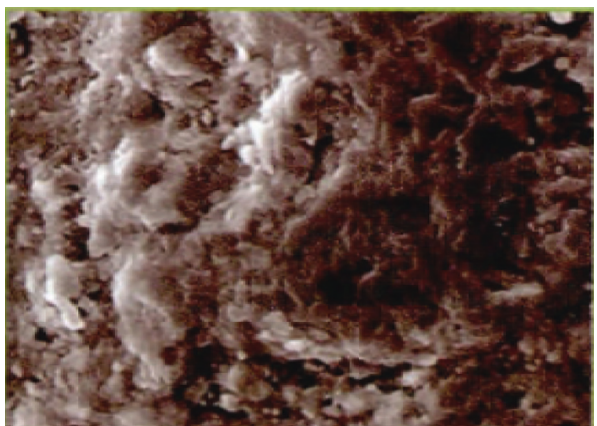

(b)

FIgURE 4: Contrast of microstructure between (a) traditional mixing and (b) vibratory mixing.

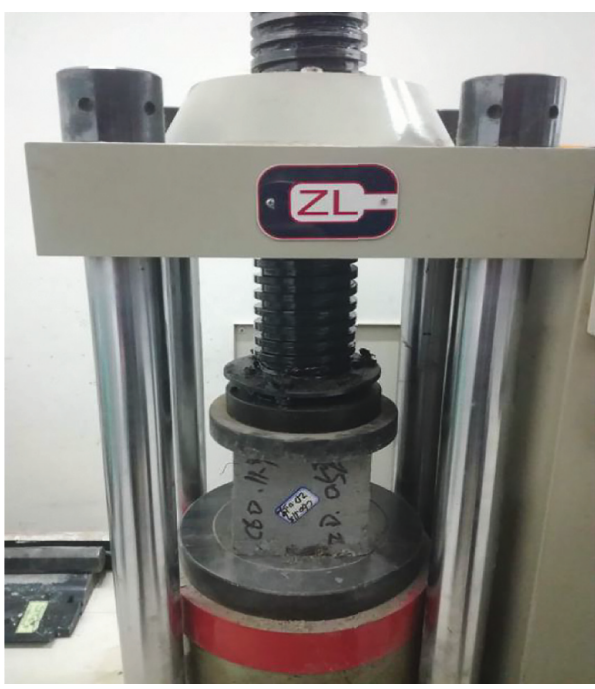

(a)

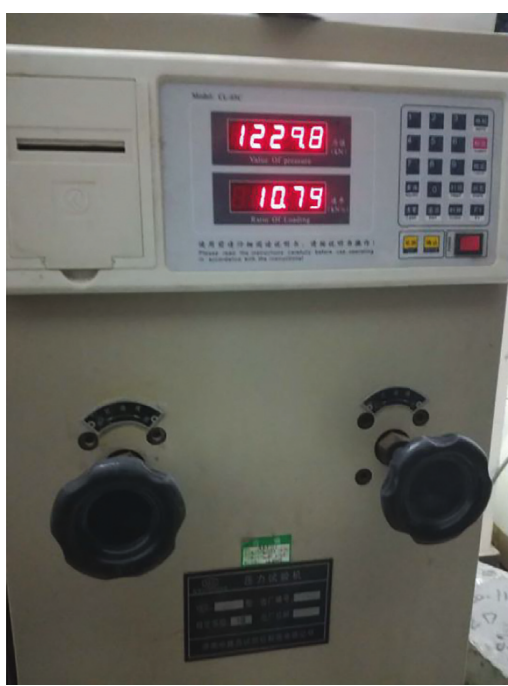

(b)

FIGURE 5: Cube compressive strength testing machine.

\section{Result and Discussion}

\subsection{Cube Compressive Strength of Steel Fiber Concrete}

4.1.1. Cube Compressive Strength of Steel Fiber Concrete Made by Traditional Stirring. It can be seen from Figure 8(a) that, for the traditional mixing method, the compressive strength of steel fiber-reinforced concrete CF50 increases as the steel fiber content increases. At the fiber content of $0.5 \%$, $1 \%, 1.5 \%$, and $2 \%$, the concrete compressive strength increases by $7.05 \%, 13.79 \%, 18.17 \%$, and $20.85 \%$. Figure 8 (a) shows that while fiber content is less than $1 \%$, the compressive strength increasing rate is faster; as the fiber content is more than $1 \%$ (e.g., $1.5 \%$ and $2 \%$ ), the compressive strength increasing rate becomes slow.

Figure 8(b) details that, similar to CF50, the compressive strength of steel fiber-reinforced concrete CF60 also improves with the increase of steel fiber content. At the fiber content of $0.5 \%, 1 \%, 1.5 \%$, and $2 \%$, the concrete compressive strength increases by $6.33 \%, 20.59 \%, 24.57 \%$, and $26.35 \%$. Figure 8 (b) also shows that while fiber content is less than $1 \%$, the compressive strength increasing rate is faster; as the fiber content is more than $1 \%$ (e.g., $1.5 \%$ and $2 \%$ ), the compressive strength increasing rate becomes slow.

Comparing CF50 to CF60, it can be found that fiberreinforced effect of compressive strength of high-strength concrete CF60 is higher than that of CF50; for example, at the same fiber content of $1 \%$, the compressive strength increases by $20.59 \%$ in CF60; in CF50, the value is $13.79 \%$. In other words, for vibratory mixing, steel fiber enhanced effect of high-strength concrete is more obvious.

4.1.2. Cube Compressive Strength of Steel Fiber Concrete Made by Vibratory Mixing. Figure 9(a) shows that, for the vibratory mixing mode, with the increase of the steel fiber content, the cubic compressive strength of concrete CF50 increases continuously. At the fiber content of $0.5 \%, 0.75 \%$, $1 \%, 1.5 \%$, and $2 \%$, the concrete compressive strength increases by $10.23 \%, 11.35 \%, 12.12 \%, 13.79 \%$, and $17.71 \%$. Figure 9 (a) shows that while fiber content is less than $0.5 \%$, the compressive strength increasing rate is faster; as the fiber content is more than $0.5 \%$ (e.g., $1.5 \%$ and $2 \%$ ), the compressive strength increasing rate becomes slow. 


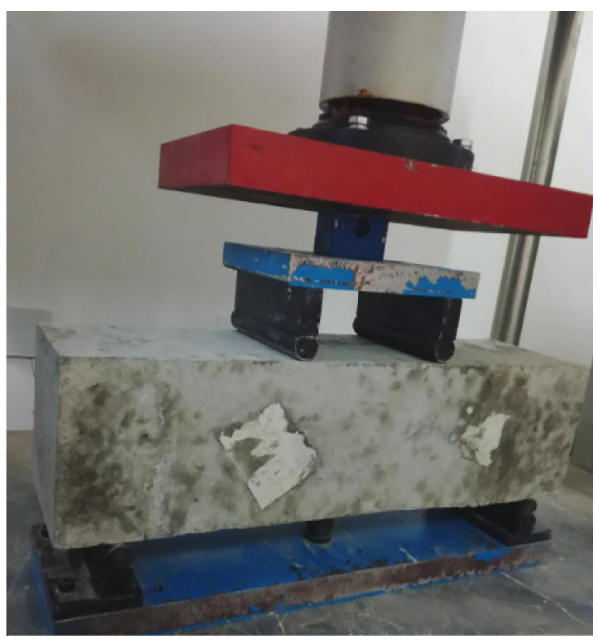

(a)

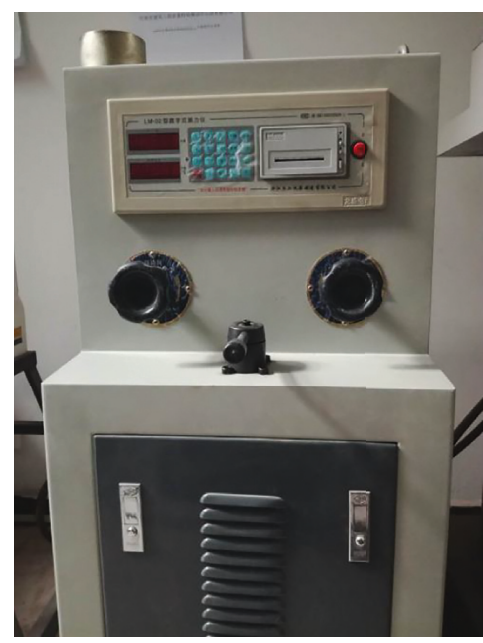

(b)

Figure 6: Flexural tensile strength test apparatus.

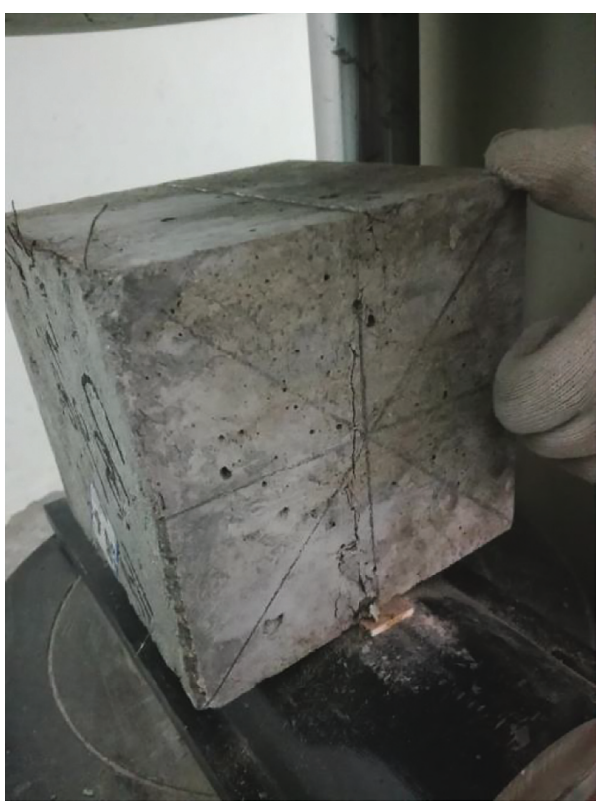

(a)

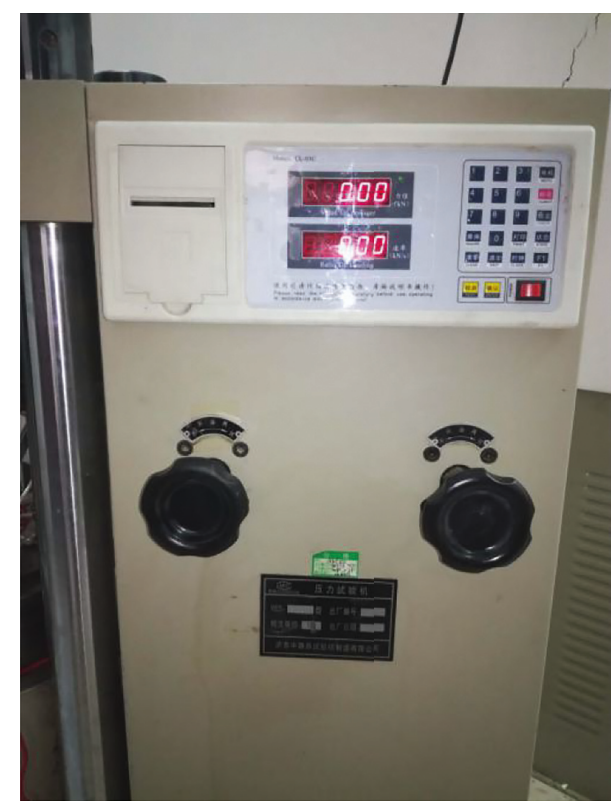

(b)

Figure 7: Cube splitting tensile strength testing equipment.

Figure 9(b) shows that, similar to CF50, the compressive strength of CF60 also improves with the increase of steel fiber content. At the fiber content of $0.5 \%, 1 \%, 1.5 \%$, and $2 \%$, the concrete compressive strength increases by $7.9 \%$, $14.14 \%, 19.96 \%$, and $22.89 \%$. Figure 9 (b) also shows that while fiber content is less than $1 \%$, the compressive strength increasing rate is faster; as the fiber content is more than $1 \%$ (e.g., $1.5 \%$ and $2 \%$ ), the compressive strength increasing rate becomes slow.

Comparing CF50 to CF60, it can be found that fiberreinforced effect of compressive strength of high-strength concrete CF60 is higher than that of CF50; for example, at the same fiber content of $1.5 \%$, the compressive strength increases by $19.96 \%$ in CF60; in CF50, the value is $13.79 \%$. In other words, for vibratory mixing, steel fiber enhanced effect of high-strength concrete is more obvious.

\subsubsection{Effect of Different Mixing Methods on the Compressive} Properties of Concrete. It can be seen from Figure 10(a) that, with the increase of the steel fiber content, the cubic compressive strength of CF50 concrete increases continuously. Comparing to traditional mixing concrete, with the same steel fiber content, the concrete made by vibratory mixing is equipped with higher compressive strength. At the fiber content of $0 \%, 0.5 \%, 0.75 \%, 1 \%, 1.5 \%$, and $2 \%$, 


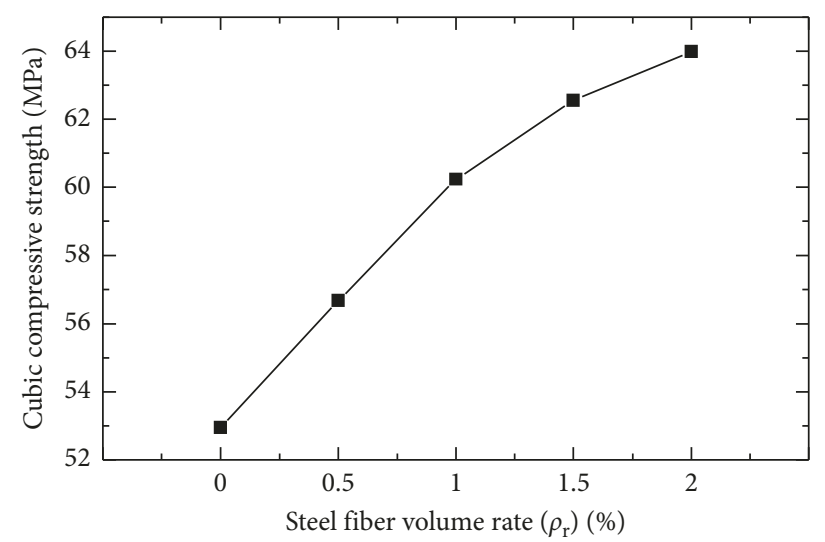

(a)

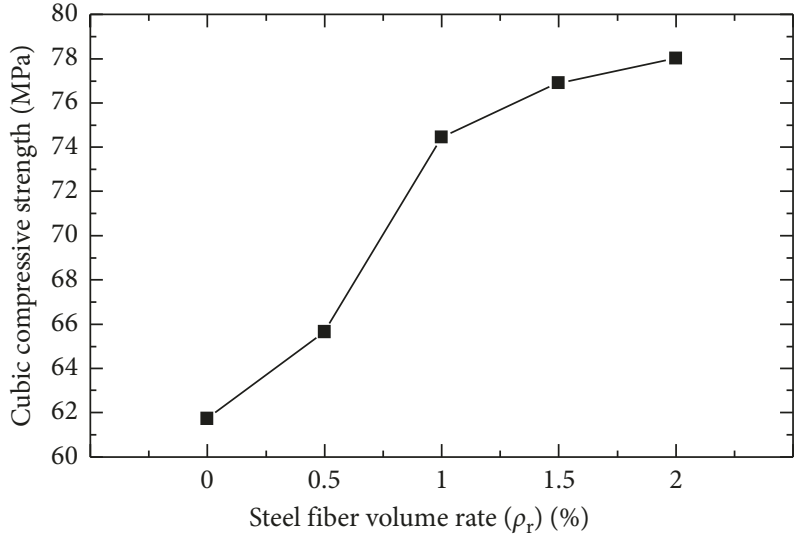

(b)

FIGURE 8: Relationship between compressive strength and steel fiber content. (a) CF50; (b) CF60.

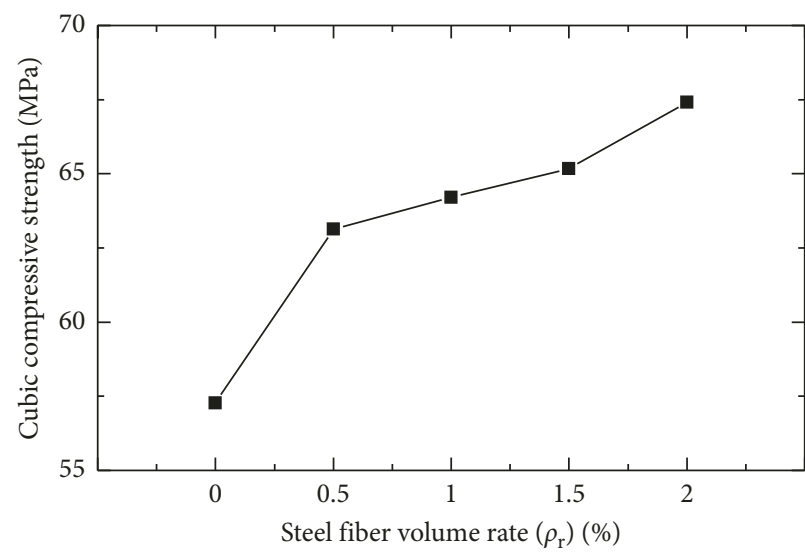

(a)

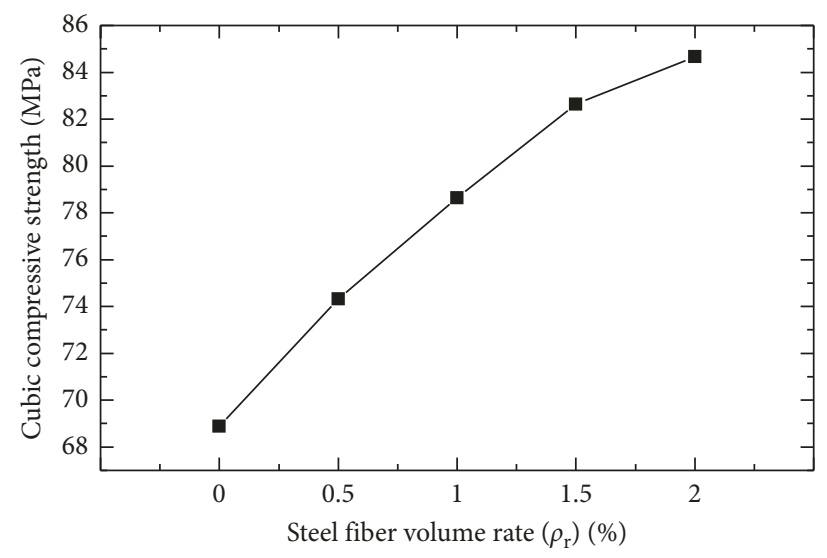

(b)

FIGURE 9: Relationship between cube compressive strength and steel fiber content. (a) CF50; (b) CF60.

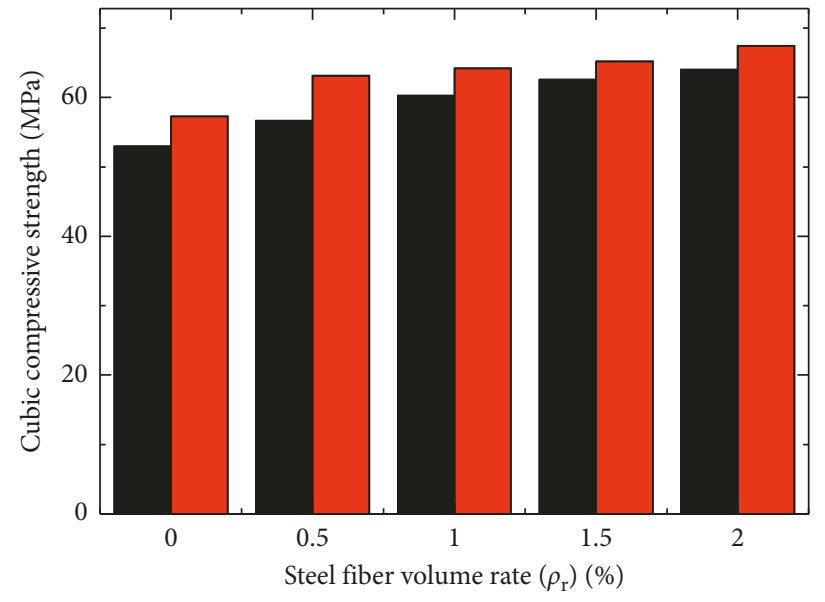

Ordinary stirring Vibratory mixing

(a)

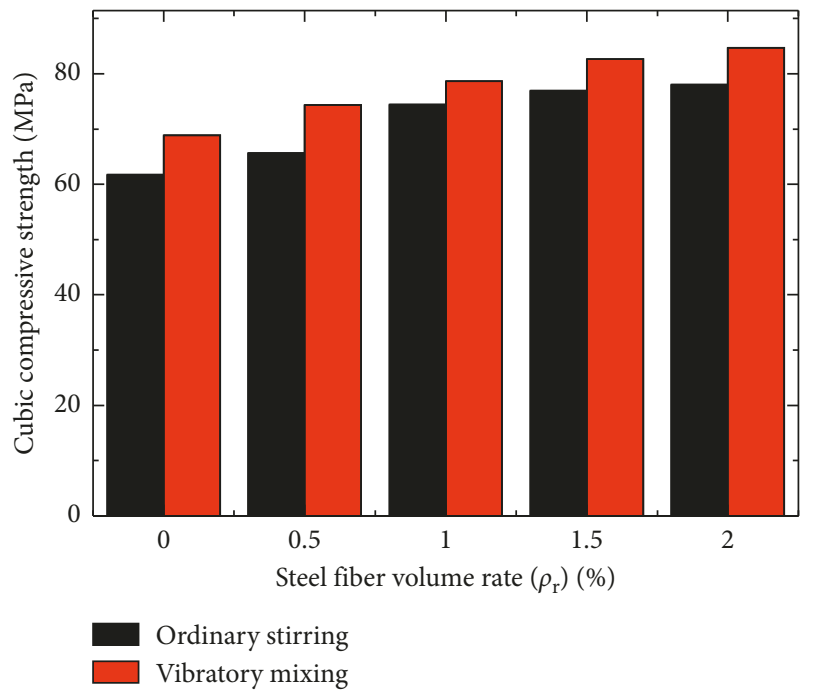

(b)

Figure 10: Effect of the mixing method on cube compressive strength of concrete. (a) CF50; (b) CF60. 


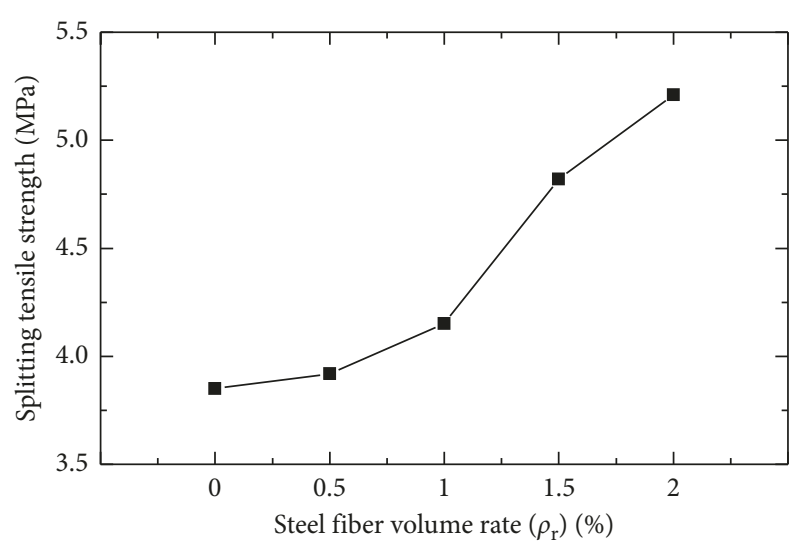

(a)

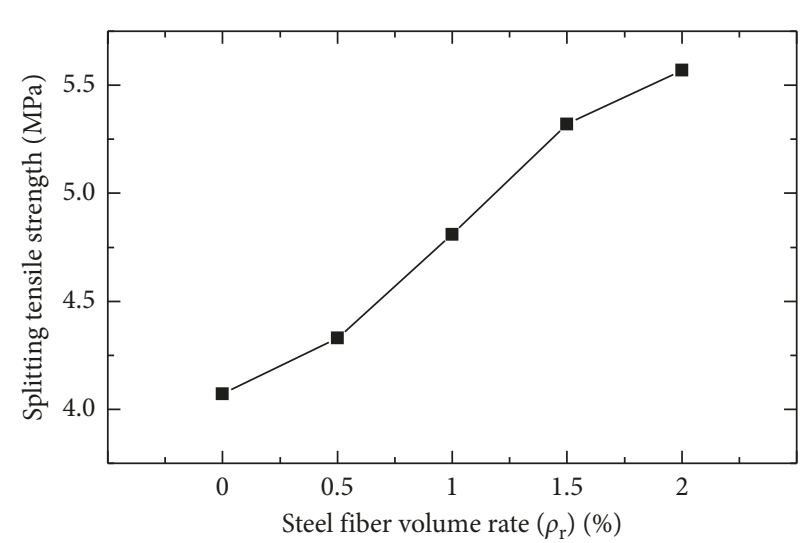

(b)

FIGURE 11: Relationship between splitting tensile strength and steel fiber content. (a) CF50; (b) CF60.

comparing to traditional mixing concrete, the compressive strength of vibratory mixing concrete increases by $8.18 \%$, $11.40 \%, 8.80 \%, 6.59 \%, 4.17 \%$, and $5.36 \%$. Figure 10 (a) also shows that while fiber content is less than $0.5 \%$, the compressive strength improvement is faster; for example, at $0.5 \%$ fiber content, the compressive strength of vibratory mixing concrete increased by $11.4 \%$; as the fiber content is more than $0.5 \%$ (e.g., $1.5 \%$ and $2 \%$ ), the compressive strength increasing rate becomes slow.

Figure 10(b) shows that, with the increase of the steel fiber content, the cubic compressive strength of CF60 concrete increases continuously. Comparing to traditional mixing concrete, at the same steel fiber content, the concrete made by vibratory mixing is equipped with higher compressive strength. At the fiber content of $0 \%, 0.5 \%, 1 \%, 1.5 \%$, and $2.0 \%$, comparing to traditional mixing concrete, the compressive strength of vibratory mixing concrete increases by $11.58 \%, 13.22 \%, 5.61 \%, 7.54 \%$, and $8.53 \%$. Figure $10(\mathrm{~b})$ also shows that while fiber content is less than $0.5 \%$, the compressive strength improvement is faster, for example, at $0.5 \%$ fiber content, the compressive strength of vibratory mixing concrete increased by $13.22 \%$; as the fiber content is more than $0.5 \%$ (e.g., $1.5 \%$ and $2 \%$ ), the compressive strength increasing rate becomes slow.

Comparing CF50 to CF60, it can be found that fiberreinforced effect of compressive strength of high-strength concrete CF60 is higher than that of CF50; for example, at the same fiber content of $0.5 \%$, the compressive strength increases by $13.22 \%$ and $11.40 \%$ in CF60 and CF50, respectively.

\subsection{Splitting Tensile Strength of Steel Fiber Concrete}

4.2.1. Splitting Tensile Strength of Steel Fiber Concrete Made by Tradition Mixing. It can be seen from Figure 11(a) that, for the traditional mixing method, the splitting tensile strength of steel fiber-reinforced concrete CF50 increases as the steel fiber content increases. At the fiber content of $0.5 \%$, $0.75 \%, 1 \%, 1.5 \%$, and $2 \%$, the concrete splitting tensile strength increases by $1.82 \%, 6.22 \%, 7.79 \%, 25.26 \%$, and
$35.41 \%$. Figure 11(a) shows that while the fiber content is less than $1 \%$, the splitting tensile strength increases slowly, while the fiber content is more than $1 \%$ (e.g., $1.5 \%$ and $2.0 \%$ ), the splitting tensile strength increases rapidly.

Figure 11(b) details that, similar to CF50, the splitting tensile strength of steel fiber-reinforced concrete CF60 also improves with the increase in steel fiber content. At the fiber content of $0.5 \%, 1 \%, 1.5 \%$, and $2 \%$, the concrete splitting tensile strength increases by $6.39 \%, 18.18 \%, 30.71 \%$, and $36.86 \%$. Figure 11(b) also shows that while the fiber content is less than $1 \%$, the splitting tensile strength increases slowly, while the fiber content is more than $1 \%$ (e.g., $1.5 \%$ and $2.0 \%$ ), the splitting tensile strength increases rapidly.

Comparing CF50 to CF60, it can be found that, at the same fiber content, fiber reinforcement effect of splitting tensile strength of high-strength concrete CF60 is higher than that of CF50; for example, at the fiber content of $1 \%$, the splitting tensile strength increases by $18.18 \%$ and $7.79 \%$ in CF60 and CF50, respectively. In other words, for traditional stirring, steel fiber enhanced effect of high-strength concrete is more obvious.

4.2.2. Effect of Steel Fiber Content on Splitting Tensile Strength of Concrete under Vibratory Mixing. It can be seen from Figure 12(a) that, for the traditional mixing method, the splitting tensile strength of steel fiber-reinforced concrete CF50 improves as the steel fiber content increases. At the fiber content of $0.5 \%, 0.75 \%, 1.0 \%, 1.5 \%$, and $2.0 \%$, the concrete splitting tensile strength increases by $4.44 \%, 7.96 \%$, $11.99 \%, 28.57 \%$, and $36.99 \%$. Figure 12 (b) also shows that while the fiber content is less than $1 \%$, the compressive strength increases slowly, while the fiber content is more than $1 \%$ (e.g., $1.5 \%$ and $2.0 \%$ ), the splitting tensile strength increases rapidly.

Figure 12(b) shows that, similar to CF50, the splitting tensile strength of steel fiber-reinforced concrete CF60 also improves with the increase obviously in steel fiber content. At the fiber content of $0.5 \%, 1 \%, 1.5 \%$, and $2 \%$, the concrete splitting tensile strength increases by $12.11 \%, 28.74 \%$, $43.23 \%$, and $66.75 \%$. 


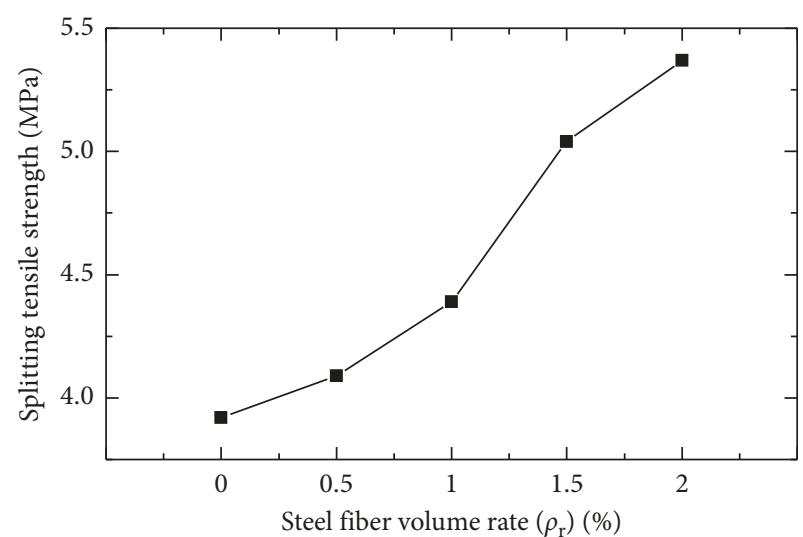

(a)

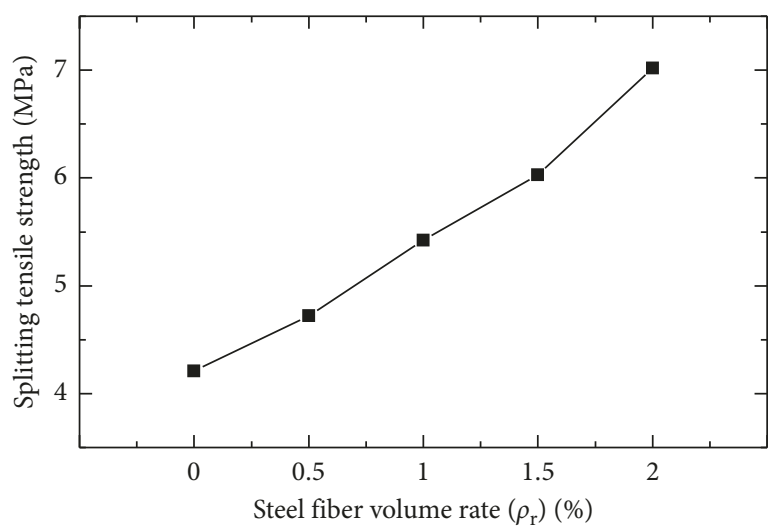

(b)

FIGURE 12: Relationship between splitting tensile strength and steel fiber content. (a) CF50; (b) CF60.

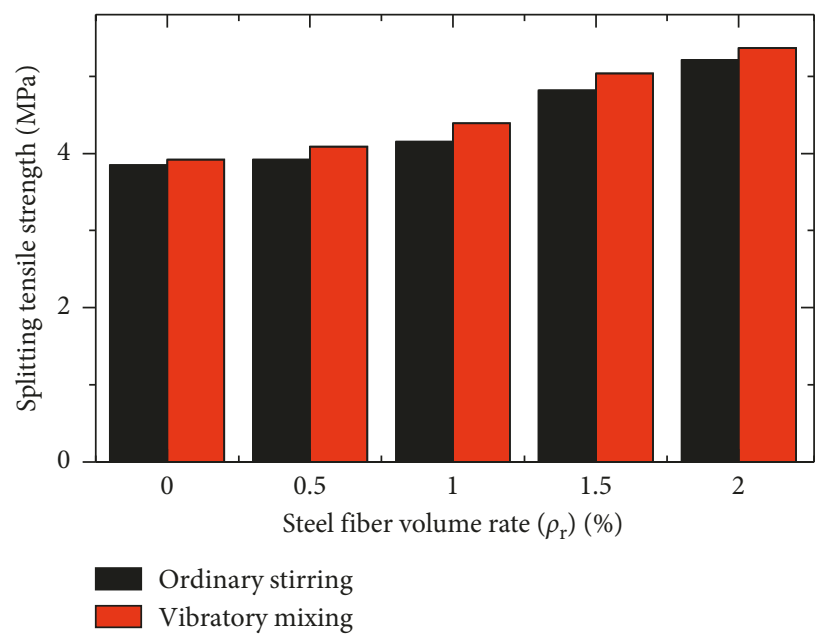

(a)

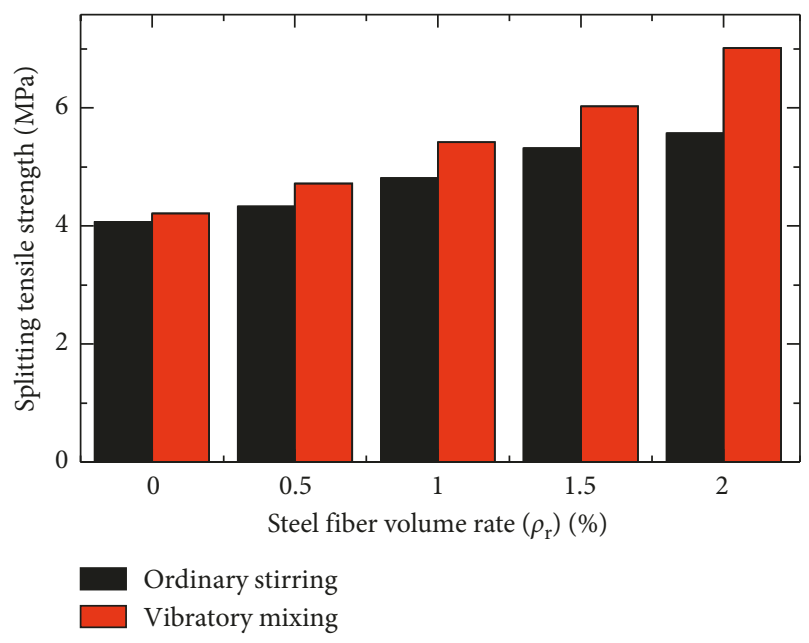

(b)

FIgURE 13: Effect of different mixing methods on the splitting tensile properties of steel fiber concrete. (a) CF50; (b) CF60.

Comparing CF50 to CF60, it can be found that, at the same fiber content, fiber reinforcement effect of splitting tensile strength of high-strength concrete CF60 is higher than that of CF50; for example, at the fiber content of $1 \%$, the splitting tensile strength increases by $28.74 \%$ and $11.99 \%$ in CF60 and CF50, respectively. In other words, for vibratory mixing, steel fiber enhanced effect of high-strength concrete is more obvious.

\subsubsection{Effect of Different Mixing Methods on the Splitting} Tensile Properties of Steel Fiber Concrete. It can be seen from Figure 13(a) that, with the increase of the steel fiber content, the splitting tensile strength of CF50 concrete improves continuously. Comparing to traditional mixing concrete, at the same steel fiber content, the concrete made by vibratory mixing is equipped with higher compressive strength. At the fiber content of $0 \%, 0.5 \%, 0.75 \%, 1 \%, 1.5 \%$, and $2 \%$, comparing to traditional mixing concrete, the splitting tensile of vibratory mixing concrete increases by $1.82 \%, 4.44 \%, 3.48 \%$,
$5.78 \%, 4.51 \%$, and $3.01 \%$. Figure $13(\mathrm{a})$ also shows that, at the fiber content of $1.0 \%$, comparing to traditional mixing, the splitting tensile strength of concrete made by vibratory mixing improves obviously.

Figure 13(b) shows that, similar to CF50, with the increase of the steel fiber content, the splitting tensile strength of CF60 concrete improves continuously. Comparing to traditional mixing concrete, at the same steel fiber content, the concrete made by vibratory mixing is equipped with higher splitting tensile strength. At the fiber content of $0 \%$, $0.5 \%, 1 \%, 1.5 \%$, and $2.0 \%$, comparing to traditional mixing concrete, the splitting tensile strength of vibratory mixing concrete increases by $3.44 \%, 9.01 \%, 12.68 \%, 13.35 \%$, and $26.03 \%$. Figure 13 (b) also shows that, at the fiber content of $2.0 \%$, comparing to traditional mixing, the splitting tensile strength of concrete made by vibratory mixing improves obviously.

Comparing CF50 to CF60, it can be found that fiberreinforced effect of splitting tensile strength of high-strength concrete CF60 is higher than that of CF50; for example, at 


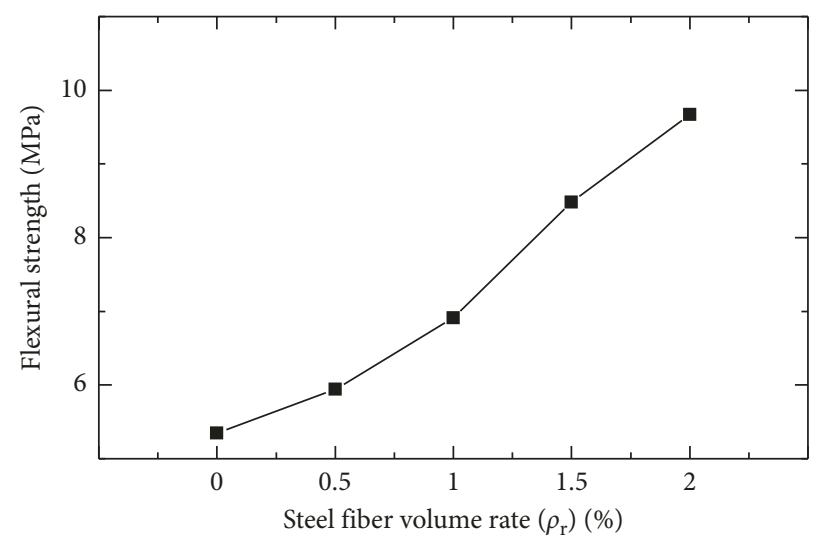

(a)

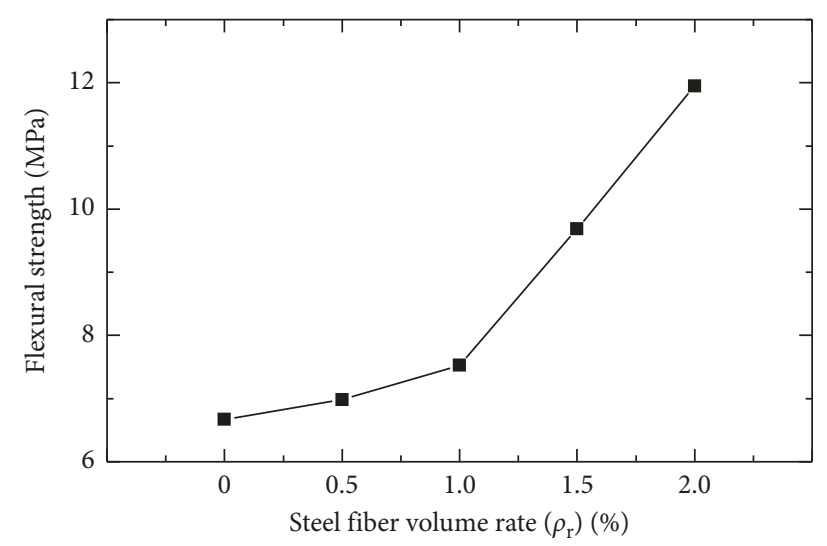

(b)

FIGURE 14: Relationship between flexural strength and steel fiber content. (a) CF50; (b) CF60.

the same fiber content of $1.0 \%$, the compressive strength increases by $12.68 \%$ and $5.78 \%$ in CF60 and CF50, respectively.

\subsection{Flexural Properties of Steel Fiber Concrete}

4.3.1. Flexural Properties of Steel Fiber Concrete Made by Tradition Mixing Conditions. It can be seen from Figure 14(a) that, for the traditional mixing method, the flexural strength of steel fiber-reinforced concrete CF50 increases obviously as the steel fiber content increases. At the fiber content of $0.5 \%, 0.75 \%, 1 \%, 1.5 \%$, and $2 \%$, the concrete flexural strength increases by $11.03 \%, 15.14 \%, 29.22 \%, 58.50 \%$, and $80.75 \%$. Figure 14 (a) also shows that while the fiber content is less than $1 \%$, the flexural strength increases slowly, while the fiber content is more than $1 \%$ (e.g., $1.5 \%$ and $2.0 \%$ ), the flexural tensile strength increases rapidly.

Figure 14(b) shows that, similar to CF50, the flexural strength of steel fiber-reinforced concrete CF60 also improves with the increase of steel fiber content. At the fiber content of $0.5 \%, 1 \%, 1.5 \%$, and $2 \%$, the concrete flexural strength increases by $17.91 \%, 27.02 \%, 68.24 \%$, and $101.86 \%$. Figure 14(b) also shows that while the fiber content is less than $1 \%$, the flexural strength increases slowly, while the fiber content is more than $1 \%$ (e.g., $1.5 \%$ and $2.0 \%$ ), the splitting tensile strength increases rapidly.

Comparing CF50 to CF60, it can be found that, at the same fiber content, fiber reinforcement effect of flexural strength of high-strength concrete CF60 is higher than that of CF50; for example, at the fiber content of $1.5 \%$, the flexural tensile strength increases by $68.24 \%$ and $58.50 \%$ in CF60 and CF50, respectively. In other words, for traditional stirring, steel fiber enhanced effect of high-strength concrete is more obvious.

4.3.2. Effect of Steel Fiber Content on Flexural Properties of Concrete under Vibratory Mixing. It can be seen from Figure 15(a) that, for the vibratory mixing method, the flexural strength of steel fiber-reinforced concrete CF50 increases obviously as the steel fiber content increases. At the fiber content of $0.5 \%, 0.75 \%, 1 \%, 1.5 \%$, and $2 \%$, the concrete flexural strength increases by $8.06 \%, 13.82 \%, 24.51 \%$, $55.76 \%$, and $72.86 \%$. Figure $15(\mathrm{a})$ also shows that while the fiber content is less than $1 \%$, the flexural strength increases slowly, while the fiber content is more than $1 \%$ (e.g., $1.5 \%$ and $2.0 \%$ ), the flexural tensile strength increases rapidly.

Figure 15(b) shows that, similar to CF50, the flexural strength of steel fiber-reinforced concrete CF60 also improves with the increase of steel fiber content. At the fiber content of $0.5 \%, 1 \%, 1.5 \%$, and $2 \%$, the concrete flexural strength increases by $8.45 \%, 19.75 \%, 47.82 \%$, and $68.94 \%$. Figure 15(b) also shows that while the fiber content is less than $1 \%$, the flexural strength increases slowly, while the fiber content is more than $1 \%$ (e.g., $1.5 \%$ and $2.0 \%$ ), the splitting tensile strength increases rapidly.

4.3.3. Effect of Different Mixing Methods on the Flexural Performance of Concrete. It can be seen from Figure 16(a) that, with the increase of the steel fiber content, the flexural strength of CF50 concrete improves continuously. Comparing to traditional mixing concrete, at the same steel fiber content, the concrete made by vibratory mixing is equipped with higher flexural strength. At the fiber content of $0 \%$, $0.5 \%, 0.75 \%, 1 \%, 1.5 \%$, and $2 \%$, comparing to traditional mixing concrete, the flexural strength of vibratory mixing concrete increases by $13.55 \%, 10.61 \%, 12.34 \%, 9.50 \%$, $11.67 \%$, and $8.69 \%$. Figure 16 (a) also shows that, at the fiber content of $0.0 \%$, comparing to traditional mixing, the splitting tensile strength of concrete made by vibratory mixing improves obviously.

Figure 14(b) shows that, similar to CF50, with the increase of the steel fiber content, the flexural strength of CF60 concrete improves continuously. Comparing to traditional mixing concrete, at the same steel fiber content, the concrete made by vibratory mixing is equipped with higher flexural strength. At the fiber content of $0 \%, 0.5 \%, 1 \%, 1.5 \%$, and $2.0 \%$, comparing to traditional mixing concrete, the splitting tensile strength of vibratory mixing concrete increases by $10.01 \%, 14.04 \%, 16.73 \%, 8.94 \%$, and $3.77 \%$. Figure 14 (b) also shows that, at the fiber content of $1.0 \%$, comparing to 


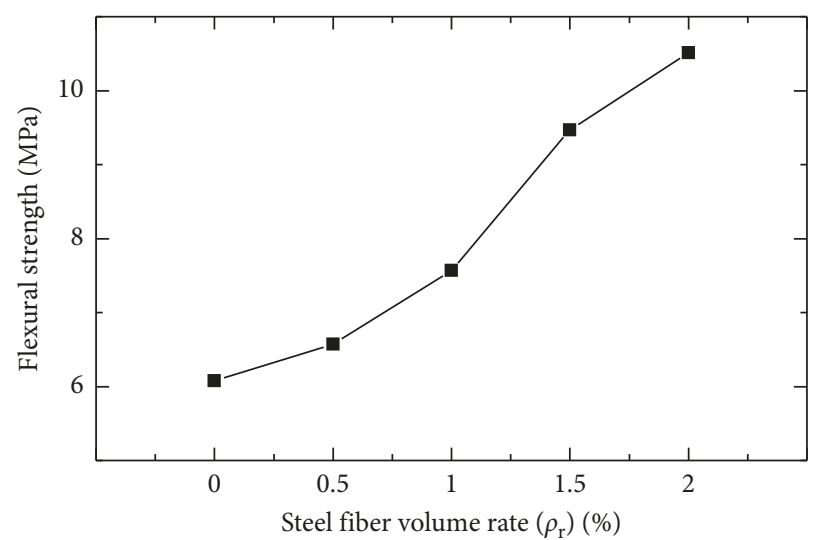

(a)

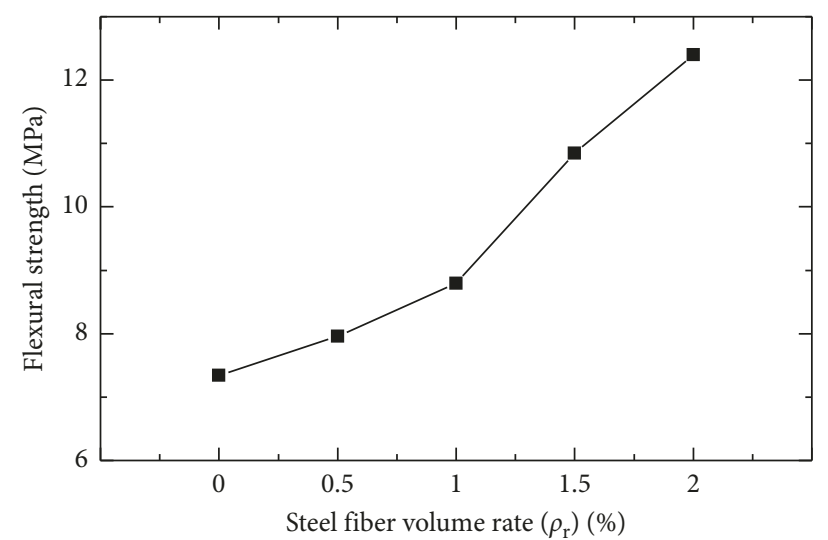

(b)

FIGURE 15: Relationship between flexural strength and steel fiber content. (a) CF50; (b) CF60.

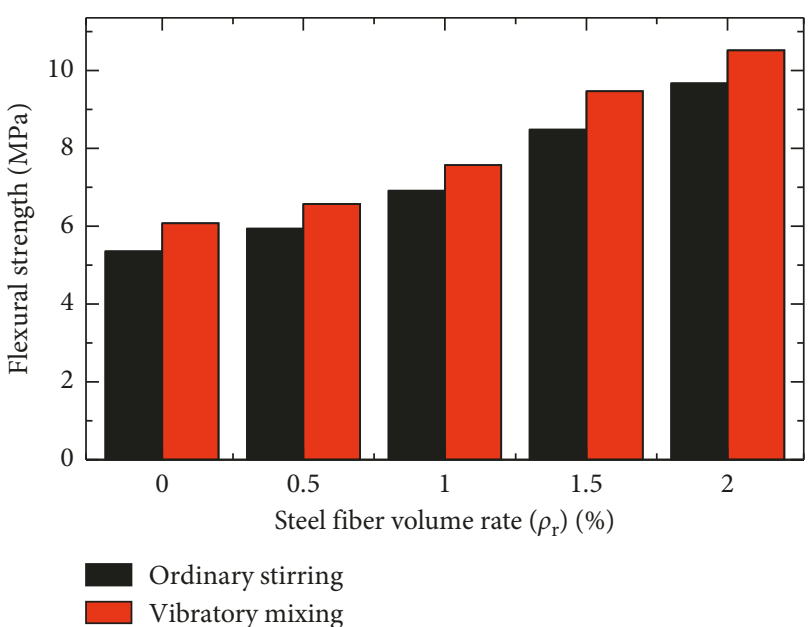

(a)

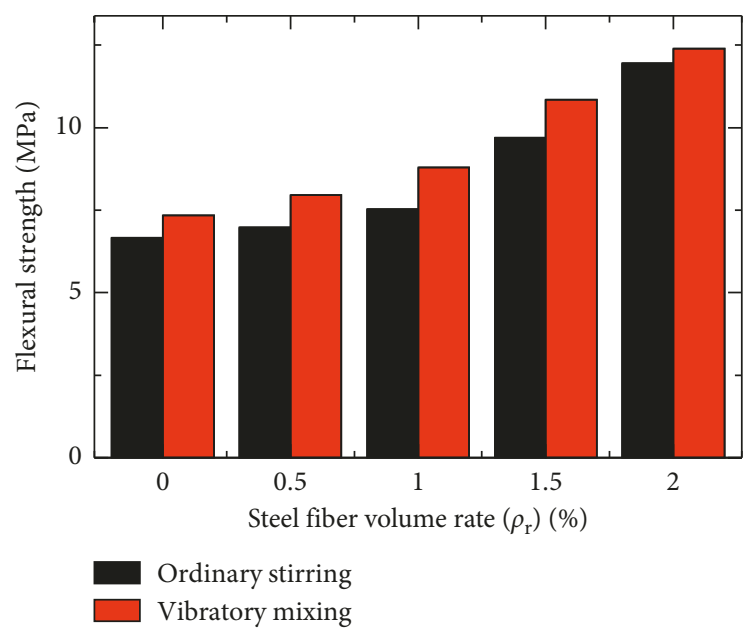

(b)

FIGURE 16: Effect of different mixing methods on the flexural strength of concrete. (a) CF50; (b) CF60.

traditional mixing, the flexural strength of concrete made by vibratory mixing improves obviously.

Comparing CF50 to CF60, it can be found that fiberreinforced effect of flexural strength of high-strength concrete CF60 is higher than that of CF50; for example, at the same fiber content of $1.0 \%$, the flexural strength increases by $16.73 \%$ and $9.50 \%$ in CF60 and CF50, respectively.

\section{Conclusion}

In this paper, the compressive strength, splitting tensile strength, and flexural strength of steel fiber-reinforced concrete made by different mix methods were analyzed. The main conclusions are as follows:

(1) With the increase in steel fiber content, all of these mechanical properties such as compression strength, flexural strength, and splitting tensile strength improve gradually; especially for flexural strength and splitting tensile strength, the steel fiber reinforcement effect is obvious. At the same fiber content, reinforcement effect of mechanical properties of high-strength concrete is better.

(2) The vibratory mixing method can make the steel fiber distribute uniformly in the concrete; as a result, comparing to traditional mixing, the vibratory mixing method can improve the compressive strength, splitting tensile strength, and flexural strength effectively. For example, compressive strength can be improved by $10 \%$, splitting tensile strength can be improved by $15 \%$, and flexural strength can be improved $12 \%$.

\section{Data Availability}

The data used to support the findings of this study are available from the corresponding author upon request.

\section{Conflicts of Interest}

The authors declare that they have no conflicts of interest. 


\section{Acknowledgments}

This work was supported by Natural Science Foundation of Henan (Grant no. 51508114), Science and Technology Program of Communications Department of Henan Province (no. 2014K37-2), Key Scientific Research Projects in Universities of Henan Province (no. 16A580001), and General Science and Technology Tackling Project of Zhengzhou City (no. 153PKJGG095) and sponsored by Henan Wanli Road and Bridge Group Co. Ltd. The authors are very grateful to the test field support of Communications Department of Henan Province.

\section{References}

[1] P. Zhang, J. Wan, K. Wang, and Q. Li, "Influence of nano- $\mathrm{SiO}_{2}$ on properties of fresh and hardened high performance concrete: a state-of-the-art review," Construction and Building Materials, vol. 148, pp. 648-658, 2017.

[2] L. Lan, A New Experimental Study on the Basic Mechanical Properties of Concrete, Dalian University of Technology, Dalian, China, 2014.

[3] G. Monti and M. Liotta, "FRP-strengthening in shear: tests and design equations," in Proceedings of the 7th International Symposium on Fiber-Reinforced Polymer (FRP) Reinforcement for Concrete Structures, Kansas City, MO, USA, November 2005.

[4] T. J. Mohammed, B. A. Bakar, and N. M. Bunnori, "Torsional improvement of reinforced concrete beams using ultra highperformance fiber reinforced concrete (UHPFC) jacketsexperimental study," Construction and Building Materials, vol. 106, pp. 533-542, 2016.

[5] S. Rahman, T. Molyneaux, and I. Patnaikuni, "Ultra high performance concrete: recent applications and research," Australian Journal of Civil Engineering, vol. 2, no. 1, pp. 13-20, 2005.

[6] P. Zhang, Y.-N. Zhao, Q.-F. Li, T.-H. Zhang, and P. Wang, "Mechanical properties of fly ash concrete composites reinforced with nano-SiO $\mathrm{S}_{2}$ and steel fiber," Current Science, vol. 106, no. 11, pp. 1529-1537, 2014.

[7] D. Guangsheng, Experimental Study on Mechanical Properties and Durability of High Strength Concrete, China University of Mining and Technology, Xuzhou, China, 2016.

[8] L. Rou, Experimental Research on Mechanism of Mechanical Properties of Concrete under Ultra-Low Temperature, Tianjin University, Tianjin, China, 2016.

[9] Y. Zheng, Y. Cai, G. Zhang, and H. Fang, "Fatigue property of basalt fiber-modified asphalt mixture under complicated environment," Journal of Wuhan University of Technology-Materials Science Edition, vol. 29, no. 5, pp. 996-1004, 2014.

[10] H. Ya-Mei and W. Li-Hua, "Study on mechanical properties of green concrete," China Rural Water and Hydropower, vol. 1, pp. 150-153, 2018.

[11] B. Jaivignesh and A. Sofi, "Study on mechanical properties of concrete using plastic waste as an aggregate," Earth and Environmental Science, vol. 80, no. 1, 2017.

[12] Y. Noma, T. Miki, K. Kono, and J. Niwa, "Study on mechanical properties of concrete using recycled materials," in Proceedings of Materials, Experimentation, Maintenance and Rehabilitation-10th East Asia-Pacific Conference on Structural Engineering and Construction, pp. 543-548, Bankok, Thailand, August 2006.
[13] A. H. Akca and N. Özyurt, "Effects of re-curing on residual mechanical properties of concrete after high temperature exposure," Construction and Building Materials, vol. 159, pp. 540-552, 2018.

[14] H. Song, S. Jin-na, and Z. Yan-ru, "A review of fiber reinforced high temperature resistant properties," in Architectural Science and Technology and Management Organizing Committee, 2016 Building Science and Technology and Academic Exchange Conference Proceedings, Beijing, China, 2016.

[15] X. Qi-Chao, Z. Jing-Cai, H. Jian, and T. J. R. Ermek, "Experimental study on the fracture properties of basalt fiber reinforced concrete," Journal of Harbin Engineering University, vol. 37, no. 8, pp. 1027-1033, 2016.

[16] P. Zhang and Q.-F. Li, "Effect of polypropylene fiber on fracture properties of high-performance concrete composites," Science and Engineering of Composite Materials, vol. 19, no. 4, pp. 407-414, 2012.

[17] L. Zhao, Mechanical Properties of Steel Fiber Reinforced Concrete and Its Application in Subway Engineering, Southwest Jiao tong University, Chengdu, China, 2017.

[18] H. N. He and W. Dong, "Experimental study on long-term restricted expansive deformation of steel fiber reinforced expansive concrete," in Proceedings of the 6th International Specialty Conference on Fiber Reinforced Materials, pp. 139142, Sherbrooke, QC, Canada, July 2017.

[19] P. Zhang, Q. Li, and Z. Sun, "Effect of polypropylene fibre on flexural properties of concrete composites containing fly ash and silica fume," Journal of Materials: Design and Applications, vol. 226, no. 2, pp. 177-181, 2012.

[20] M. A. Al-Osta, M. N. Isa, M. H. Baluch, and M. K. Rahman, "Flexural behavior of reinforced concrete beams strengthened with ultra-high performance fiber reinforced concrete," Construction and Building Materials, vol. 134, pp. 279-296, 2017. 


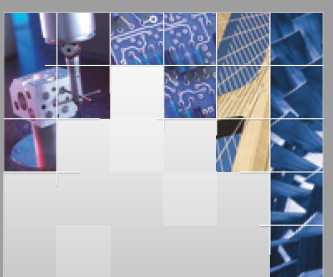

\section{Enfincering}
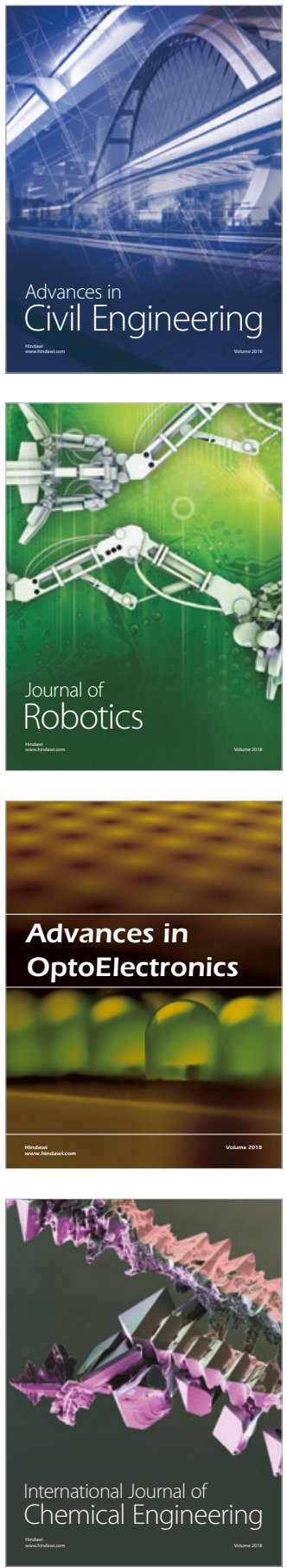

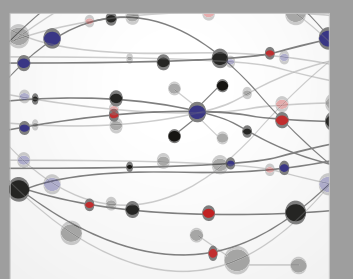

\section{Rotating \\ Machinery}

The Scientific World Journal

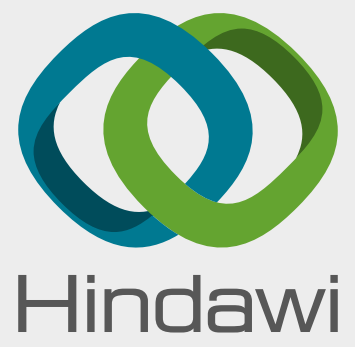

Submit your manuscripts at

www.hindawi.com
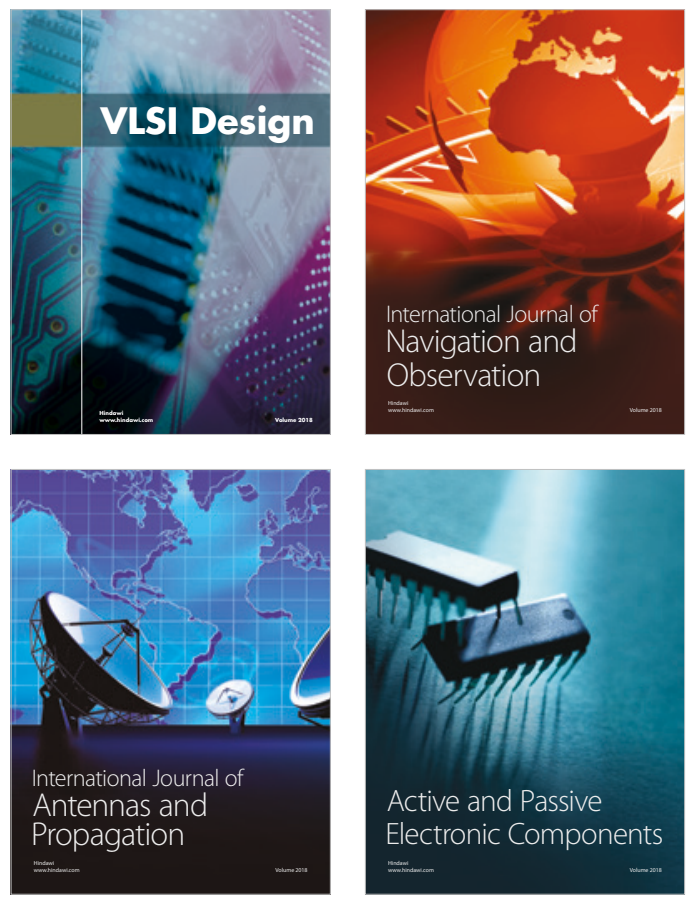
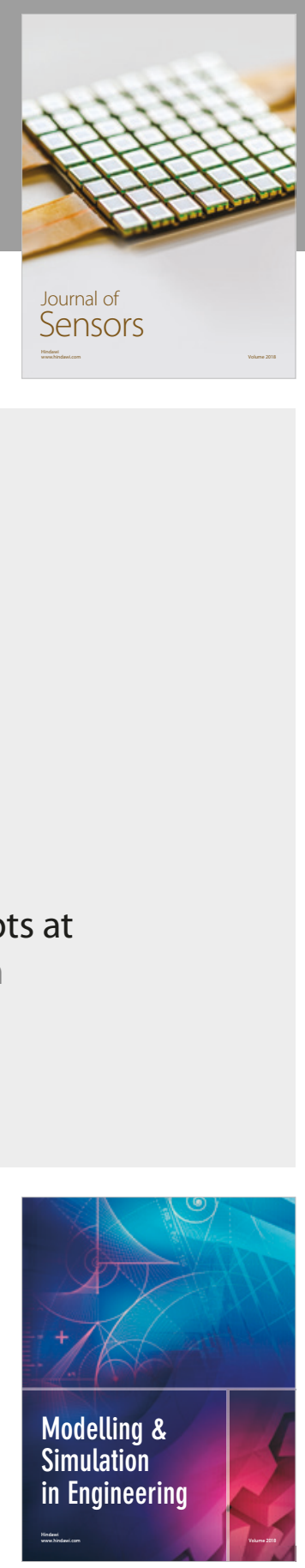

\section{Advances \\ Multimedia}
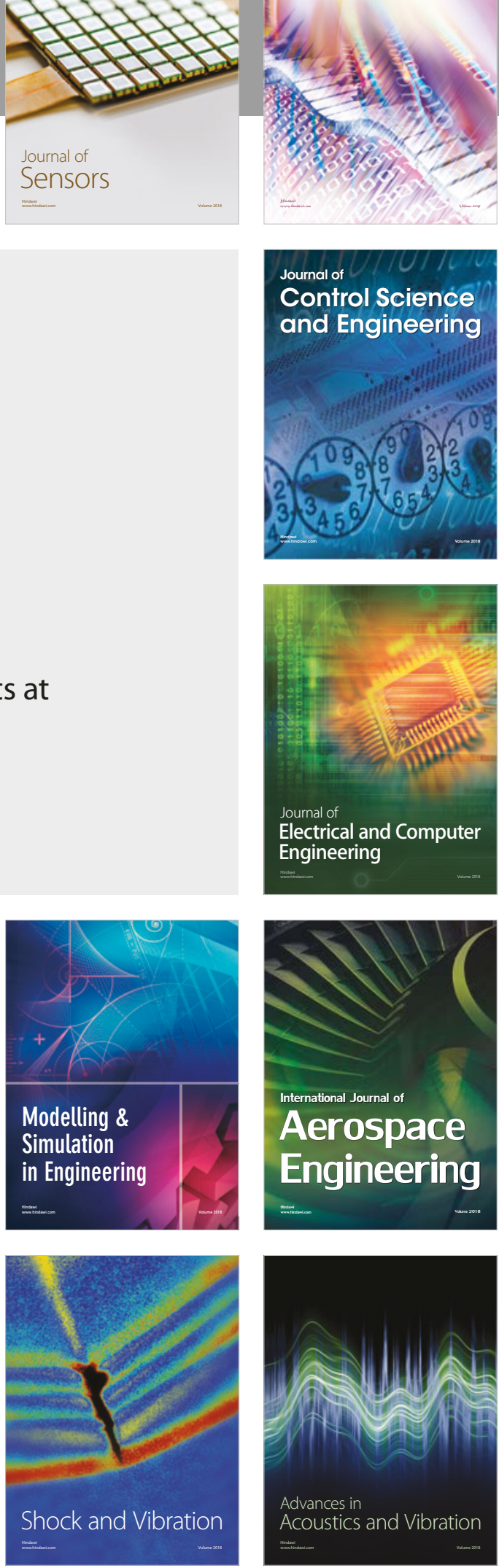